position. These marks are clear, but at the usual working distance of the anaesthetist from the machine, the position of the control dial can be overlooked.

A coloured sticker placed at the OFF position on the control dial makes it obvious that the vaporizer is "off", or turned "on." In comparison with other safety devices for anaesthetic machines this is simple, cheap, and available to all anaesthetists.

Geoffrey G. Coleshill MB CH в DA

Central Interlake Clinic

Teulon, Manitoba, ROC 3B0

\section{Malfunctioning unidirectional valves of Ohmeda Series 5 and 5 A carbon dioxide absorbers}

To the Editor:

Coincidental with the introduction of a shared mass spectrometer for respiratory and anaesthesia gas analysis into the main operating room suite at the Royal Victoria Hospital, was the introduction of Ohmeda Series 5 carbon dioxide absorbers onto 15 Boyle $\mathrm{M}$ anaesthesia machines and the subsequent conversion from Mapleson D to semi-closed circuit for delivery of anaesthesia. Fresh gas flow was delivered through MDM flow meters and was approximately $2-3 \mathrm{~L} \cdot \mathrm{min}^{-1}$.

The on-line detection of inspired and expired carbon dioxide enabled us to detect the repeated malfunction of the unidirectional valves of many of these absorbers, such that wo instituted a survey of the problem during a three-week period. Fourteen incidents of malfunctioning unidirectional valves on nine units were reported involving both the inspiratory (five) and expiratory (nine), valves.

Our ability to detect this problem was entirely dependent on the niass spectrometer which was programmed to aler the anaesthetist at a $\mathrm{PE}^{\prime} \mathrm{CO}_{2}>5 \mathrm{mmHg}$. It was this programmed alert which prevented, as far as we were aware, damage to our patients, but clearly the situation was far from satisfactory. We were consequently obliged to inform the manufacturer (Ohmeda, Rexdale) and Health and Welfare Canada via their Medical Devices Problem Reporting Program of our experiences and request a solution to the problem.

Investigation of the problem by the company revealed reproducible malfunction of the valve assembly. Ohmeda determined that this was the result of the flow characteristics of the gases in the breathing circuit, in combination with the effects of surface tension from the accumulation of condensation on the valve components.
Subsequent redesign of the valve disc, disc cage and valve seat of the unidirectional valve assembly preceded field testing of the new components during which no incidence of malfunction was reported. Consequently, an urgent Medical Device Recall was issued by Ohmeda in May 1988 to all users of Series 5 and 5A Carbon Dioxide Absorbers calling attention to the problem and offering replacement of the existing valve assemblies.

We have used the redesigned valve system on these absorbers since January 1988, and are satisfied that the problem we have described has been resolved.

David $G$. Whalley MB CH B FFARCS FRCPC

Department of Anaesthesia

Royal Victoria Hospital

687 Pine Avenue West

Montréal, Québec H3A 1A1

\section{REPLY}

Ohmeda sincerely appreciates $D r$. Whalley's cooperation and assistance in discussing his experiences with us. Such communication is essential for manufacturers such as Ohmeda to respond to the ever-changing clinical requirements of the profession with innovative product evolution and development.

In this irstance, Oluneda has released an aduanced design of unidirectional valve for Carbon Dioxide Absorbers. This valving system is available to Canadian users of Ohmeda Series 5 and $5 A$ Absorbers in accordance with the following Recall Letter dated May 31, 1988.

\section{UAGENT - MEDICAL DEVICE HECALL}

Ohmeda (Medishield) carbon dioxide absorbers Series $5,5 A$ only

Several users of Series 5 abscrbers have reported occasionally monitoring higher than expected $\mathrm{CO}_{2}$ levels in the breathing circuit gases during controlled ventilation.

These reports indicated intermittent sticking in the open position of the mica disc used in the inhalation and exhalation valves

No patient injury has been reported and in each report the $\mathrm{CO}_{2}$ levels were restored to expected levels when the mica dise operation returned to normal ei ther by its own accord or by user intervention such as tapping the valve housing to free the disc from its "sticking" position.

Ohmeda research suggests this inhalation/ exhalation valve mal function is a result of the flow charasteristics of the breathing circuit gases when combined with the sur face tension effects of condensate accumulations on the ultra light mica valve diso, valve disc oage and valve seat assemblies.

As a result of this research, Obmeda has redesigned these portions of the inhalation/ exhalation valves to minimize the effects of condensate on valve operation.

To avoid the potential of higher than anticipated $\mathrm{CO}_{2}$ levels resulting from this mal function and to 
up and over the screen will prevent separation, while greater strap tension and overhead tape pull on the support will improve jaw contact and control, which can be difficult in cases of sagging chins and receding mandibles. ${ }^{1}$

The apparatus cannot be left unobserved, but, compared with other devices ${ }^{\mathbf{8}, 9}$ it is easily assembled using common theatre items, and interferes little with tucking away the tails of operative drapes cast over the screen. In most cases, the tape technique has proved effective in assisting maintenance of the airway during mask anaesthesia.

The Author is indebted to Mr. J. Campbell, Consultant Orthopaedic Surgeon, Broadgreen Hospital, for permission to submit the accompanying photograph. Patient consent was also obtained

Michael A. Lyew, MB Bs FFARCS

Department of Anaesthesia

Broadgreen Hospital

Thomas Drive

Liverpool

L14 3LB

United Kingdom

Address correspondence to: Dr. M.A. Lyew, Department of Anaesthesia, Montreal Children's Hospital, 2300 Tupper Street, Montreal, Quebec H3H IP3

\section{REFERENCES}

1 Evans PJD, MCQuay $H J$, Bullingham RES, Lloyd JW, Moore RA. Maintaining the airway. Was Guedcl wrong? Inside or outside the mouth? Araesthesia 1982; 37: 701-2.

2 Parrick MR. Airway manipulations. In: Taylor TH, Major E. Hazards and Complications in Anaesthesia. Edinburgh. Churchill-Livingstone, 1987: 329-55.

3 Guildner CW. Resuscitation - opening the airway: a comparative study of techniques for opening an airway obstructed by the tongue. JACEP 1976; 5: 588-90.

4 Snow JC, Kripke BJ, Norton ML, Chandra P, Woodcombe $H A$. Comeal injuries during general anesthesia. Anesth Analg 1975; 54; 465-7.

5 Conway $C M$. Neurological and ophthalmic complications of anaesthesia. I $n$ : Churchill-Dayidson HC. A practice of andesthesia. 5th ed. London. Lloyd-Luke, 1984: 793-9.

6 Anamihanarayan C, Rolbun SH, Hew E. Facial paralysis following mask anaesthesia. Can J Anaesth 1988; 35 102-3.

7 Pollak $H$. Anesthesia gadgets. Anesthesiology 1979; 50: 475-6.

8 Smith 1. A chin support for unconscious patients. A modification of the Guy's suspension apparatus. Anaesthesia 1974; 29: 740-2.

9 DeLeeuv $P$. An aid to airway maintenance during operative sedation. Anesthesiology 1984; 60: 388.

\section{Shivering following retrobulbar block}

To the Editor:

We would like to congratulate Drs. Lee and Kwon on their excellent case presentation of "Shivering following retrobulbar block". ${ }^{1}$ We are pleased to see that they support our hypothesis regarding the mechanism by which the central nervous system complications after retrobulbar block occur. ${ }^{2}$

However, in our experience shivering is not only a warning sign, it is indeed one of the protean manifestations of brainstem anaesthesia. These may include hemiparesis, aphasia, convulsions, confusion, loss of consciousness; changes in blood pressure, heart rate, and even asystole; apnoea or change in respiratory pattern; vomiting and shivering. We have observed that amaurosis, pupillary dilatation, and partial akinesia of the extraocular muscles of the contralateral eye may occur without any other signs. We consider this sign to be pathognomonic of central spread of the local anaesthetic agent and it should be looked for whenever any abnormal reaction occurs following retrobulbar block. Any one of these complications may occur singly or in combination. Many cases previously attributed to be vasovagal responses may have been episodes of central spread.

As more and more anaesthetists are now becoming involved in administering and monitoring local ophthalmic anaesthesia, a greater understanding of these complications will be reached, and we believe that better quality of patient care will then be achieved.

\section{J. Martin V. Nicoll FFa(SA) \\ P. Arun Acharya FFARCS \\ K. Roger Edge FFA(SA) \\ Saeed Baguneid MD \\ Stanley Brown fFa(SA) \\ Geeta Shetty FFARCS \\ Department of Anaesthesia}

King Khaled Eye Specialist Hospital

P.O. Box 7191

Riyadh 11462

Saudi Arabia

\section{REFERENCES}

1 Lee $D S, K$ won $N J$. Shivering following retrobulbar block. Can J Anaesth 1988; 35: 294-6.

2 Nicall JMV, Acharya PA, Ahlen K, Baguneid S, Edge $K R$. Central nervous system complications after 6000 retrobulbar blocks. Anesth Analg 1987; 66: 1298-1302. 